\title{
Fidelity of computational modelling of offshore jacket platforms
}

\author{
Margi Vilnay PhD \\ Lecturer, School of Science, Engineering and Technology, Abertay \\ University, UK (corresponding author: m.vilnay@abertay.ac.uk) \\ (Orcid:0000-0003-3916-8153) \\ Valdemaras Sivickij MEng \\ Engineer, Bridges Department, Cardiff, WSP \\ Frazer Watters MEng \\ Engineer, UK Verification Centre, DNV GL
}

\author{
Cornelia Doerich-Stavridis PhD \\ Lecturer, School of Science, Engineering and Technology, Abertay \\ University, UK \\ Leon Chernin PhD \\ Lecturer, School of Science and Engineering, University of Dundee, \\ Dundee, UK
}

Fixed offshore jackets are the most commonly adopted rigs for exploration of offshore oil and gas resources. The present paper focuses on the modelling of a 4-legged X-braced jacket type platform using nonlinear finite element analysis. The nonlinear effects of joint flexibility, piled foundations and geometrical imperfections on the platform behaviour are investigated. Joint flexibility is modelled by introducing rigid or flexible joints into the jacket beam element model. A hybrid model, with the critically-loaded leg and connected joints built using shell elements, is applied for the investigation of localised effects on increasing joint flexibility. The soil-pile interaction is modelled using sets of decoupled springs distributed along the piles. The geometrical imperfections, generated based on the failure modes of the platform, are introduced in the compression legs of the jacket. The platform is loaded by operational and environmental loads. The environmental loads are gradually increased until platform failure occurs. The findings of the paper indicate that incorporation of joint flexibility and piled foundations result in the reduction of platform yielding and ultimate strength. The piled foundation affects platform stiffness severely. The imperfections increase platform deformability in the elastic rage and lead to dramatic reduction of jacket base shear capacity.

\section{Notation \\ E unfactored (characteristic) global environmental actions \\ $l \quad$ element length \\ $R_{\text {ult }} \quad$ ultimate resistance of the structure at the state of collapse \\ SF base shear force \\ $w_{\mathrm{i}} \quad$ out-of-straightness amplitude (equivalent imperfection) \\ $\delta \quad$ maximum deformation in the jacket \\ $\bar{\lambda} \quad$ reduced slenderness ratio for column buckling \\ $\lambda_{\text {ult }} \quad$ load proportionality factor at collapse \\ $\sum \mathrm{SF}_{x(y)}$ sum of shear forces at the piled foundation in the $X$ (or $Y$ ) direction}

\section{Introduction}

Steel platforms are extensively used in exploration of offshore oil and gas, the first of which were erected in the Gulf of Mexico in 1947 (Clauss et al., 1992). Of these platforms, fixed offshore jacket-type structures are the most commonly adopted rigs for shallow water depths (Skallerud and Amdahl, 2002). They are exposed to harsh offshore conditions during storms and hurricanes and, therefore, are designed to resist high environmental loads generated from wave, current, wind, snow and ice. The cyclic nature of the environmental loads causes fatigue-related strength reduction (Ersdal, 2005). Another important factor in the structural design of the platforms is the length of the service life. A majority of the North Sea platforms has, for instance, reached the end of their designed service life and as such are currently operating out-with their life expectancy (The UK Oil and Gas Industry Association (OGUK, 2017)). The structural performance of platforms has been affected by the aggressive marine environment through material deterioration (e.g. steel corrosion) leading to the reduction of platform durability (Stacey et al., 2008). Many platforms have additionally undergone significant structural changes, such as topside extensions to accommodate new, more efficient oil extraction equipment or additional living quarters. Therefore, reliable analysis procedures, based on the application of advanced computational methods and the development of highly detailed models, are required to keep platforms operating at a safe and efficient level.

Over the last decades, analysis and assessment methods of offshore platforms have developed significantly (Chandrasekaran, 2015; Hellan, 1995; Skallerud and Amdahl, 2002). However, several catastrophic events such as the collapse of the Alexander Kielland platform in 1980 (Lancaster, 2000) and the Piper Alpha disaster in 1993 (Paté-Cornell, 1993) have placed an increased focus on the evaluation of the ultimate 
strength of the platform. The ultimate strength and actual design life can only be accurately assessed by considering nonlinear effects of joint flexibility, piled foundations and geometrical imperfections on the platform behaviour.

\subsection{Joint flexibility}

The design of offshore tubular space frames widely used in offshore jacket platforms usually consists of several tubular legs (chords) with a large number of tubular bracing members (Ueda and Rashed, 1990). Tubular joints constitute one of the main challenges in the design, construction and maintenance of these jackets (OETB, 1990). The design of tubular joints is generally based on the strength and detailing requirements, in which two principal considerations have to be addressed fatigue behaviour and static strength. In practice, the measure of the structural capacity of an overall jacket structure is normally taken when the first yielding at the highest stressed point in a structural component occurs. However, for unstiffened tubular joints, first yielding has never been used as a criterion for ultimate capacity. Rather, this is determined on the basis of a maximum allowable displacement or limit load (Skallerud and Amdahl, 2002). In compression, the capacity of a tubular joint can be described by an ultimate limit load. However, when a tubular joint is loaded in tension, the matter is further complicated. Although a limit load may be applied to a joint, it occurs at such high levels of deformation that the joint suffers severe ductile crack growth (Skallerud and Amdahl, 2002), indicating that tensile capacity must be reduced if failure is to be considered at the first sign of cracking. The implementation of this theory in modelling practice resulted in neglecting joint flexibility. It is usual practice within the offshore industry (e.g. ISO 19900) to assume rigid joints and the length of a member equal to the distance between centres of joints connected by it (i.e. centre-to-centre approach). However, these assumptions contradict the real conditions, since joints undergo deformation particularly when members in the jacket are pushed beyond the elastic response. Recent experiments have shown that the amount of force required to achieve a complete failure of tubular joints is significantly greater that those loads that cause initial yielding in members of the jacket platform (Bouwkamp et al., 1980). In an attempt to consider some joint deformation in the design, joint capacity equations have been developed (Dier and Lalani, 1998). These equations consider the development of various failure mechanisms, depending on the type and magnitude of applied load, and can be used for evaluation of the limit values. When the effect of joint flexibility needs to be accounted for directly, the joints are modelled either with shell elements, which account for the deformation within the joint explicitly, or springs, which consider elastic behaviour of the joint based on parametric equations (Dier and Hellan, 2002). Additionally, special type elements were developed for this purpose (Holmås, 1987; Holmås et al., 1987).
Several researchers have investigated the effect of joint flexibility on the overall behaviour of a jacket platform (Bouwkamp et al., 1980; Dier and Hellan, 2002; Hellan, 1995; Holmås, 1987; Holmås et al., 1987; Mendoza Espinosa, 2017; Mirtaheri, 2009). These studies reported that introducing joint flexibility led to significant changes in the structural response. However, the effect of joint flexibility on platform strength was not clear. For example, Hellan (1995) investigated the impact of joint flexibility on the ultimate strength of four jacket models representative of typical North Sea platforms. The models employed different strategies in considering joint flexibility. Structural members were modelled using either the centre-to-centre approach with rigid joints or the face-to-face approach with rigid or flexible joints. Here, the face-to-face approach assumed length of a brace member equal to distance between faces of legs, while legs were modelled as continuous. This configuration corresponds to the actual length of brace members, since braces are welded to the faces of the legs resulting in shorter member lengths. The study indicated that the centre-to-centre approach is sufficiently conservative and joint flexibility can be disregarded. Mirtaheri (2009) performed a non-linear static push-over analysis on platforms with individual T- and Y-joints modelled as rigid or flexible. To estimate the effect of joint flexibility on the strength and stiffness of the platform, the load-deformation $(P-\delta)$ behaviour was studied analytically by examining the response of deck displacement to the base shear. The authors reported that the platform was considerably stiffer when joints were modelled as rigid. Consequently, stiffness and ultimate capacity of the jacket platform modelled without joint flexibility can be overestimated leading to a non-conservative design of the structure. According to ISO 19902 (BS EN ISO 19902:2007 (BSI, 2007)), flexibility of the joint does not significantly affect the axial forces in a simple framework, but inclusion of the joint flexibility modifies member end- and mid-span bending moments and can reduce the overall stiffness of the framework, thus increase the main periods of vibration by $3-6 \%$.

\subsection{Piled foundation}

Fixed jacket structures are generally piled to the sea floor. Piles are installed primarily to resist the axial bearing actions due to gravity of the structure, overturning moment and global base shear force generated from environmental actions (Skallerud and Amdahl, 2002). The foundation failure mechanisms include lateral soil failure, induced by lateral forces in piles and axial soil failure, which includes pull-out in tension and punchthrough in compression. In the case of lateral soil failure, a portal frame mechanism develops in the piles below the mud-line. This results in formation of plastic hinges in the piles at the mud-line and development of maximum bending moment just below the mud-line (Norske Veritas, 1999). In the case of axial soil failure, the whole platform rotates as a 'rigid body' about a horizontal axis in the foundation. 
In practice, the soil-structure interaction is accounted for by modelling the pile embedded in the soil (an explicit approach), or by attaching to the pile a series of uncoupled springs representing the soil (an implicit approach) (Skallerud and Amdahl, 2002). In the latter option, the springs should accurately capture the non-linear mechanical properties of the soil. Several research studies investigated the effect of soil-structure interaction on offshore platforms (Azadi, 1998; Gilbert et al., 2010; Mostafa and El Naggar, 2004). Azadi (1998) investigated the influence of soil-structure interaction of an actual eightlegged jacket in the North Sea by means of a static push-over analysis. It was reported that soil-structure interaction increased platform displacements but had insignificant effect on the ultimate strength. This implies that the piled foundation was stronger than the jacket.

\subsection{Geometrical imperfections}

Platform strength can also be affected by the imperfections introduced at the fabrication stage. The imperfections can significantly reduce the buckling strength of compression elements, because it is generally dependent on the amount of deformation within the element (Skallerud and Amdahl, 2002). If the imperfections are not considered, the simulated buckling capacity of the members in the jacket is unrealistically high. Two main types of imperfections in structural elements include (a) residual stresses and (b) geometric deviations. Residual stresses arise from both manufacturing of the profile and fabrication of the structure. This includes stresses induced during the welding process, which generates lateral distortions and misalignment of structural elements. Fabrication-induced residual stresses are usually redistributed in adjacent elements of the jacket. Geometric imperfections consist of cross-sectional variations (i.e. plate thickness, tube diameter, shape distortions) and axial out-of-straightness. Such imperfections are primarily caused by the manufacturing and fabrication processes of the profile. Experimental observations on K-braced plane frames indicated that significant compressive residual stresses in the range of $30 \%$ of the yield stress had a substantial effect on the occurrence of first member buckling, but resulting effect of fabrication-induced residual stresses on the ultimate strength of the system was relatively small (Bolt, 1995; Bolt et al., 1996). Therefore, the fabrication-induced residual stresses can be neglected in the analysis, while element geometric imperfections should be accounted for (Skallerud and Amdahl, 2002). Some codes (e.g. ECCS, Eurocode 3) provide design equations for element buckling where the out-of-straightness captures the effect of both geometric deviations and residual stresses.

For a thin-walled tubular beam made of mild steel, an equivalent imperfection is given by (Skallerud and Amdahl, 2002)

1. $\frac{w_{\mathrm{i}}}{l}=0.0015\left(1-\frac{0 \cdot 2}{\bar{\lambda}}\right)$ where $w_{\mathrm{i}}$ is the out-of-straightness amplitude (equivalent imperfection), $l$ is the element length and $\bar{\lambda}$ is the reduced slenderness ratio for column buckling. Equation 1 implies that equivalent imperfection can be considered by introducing a mid-span deflection of $0 \cdot 15 \%$ of the element length. Furthermore, sufficiently accurate results can be obtained by using a constant amount of out-of-straightness over the whole range of slenderness.

When the out-of-straightness imperfection distorts the element shape in the direction opposite to the critical buckling mode, the buckling strength increases. Therefore, the imperfections can be either favourable or unfavourable. In the analysis of offshore platforms, a conservative approach, which assumes the most unfavourable imperfection, is required for ultimate strength assessment (Skallerud and Amdahl, 2002). Hellan (1995) suggested that the most conservative case corresponds to imperfections assigned in the direction of the global base shear.

This paper examines the extent by which the computational prediction of the ultimate strength of jacket platform is affected by joint flexibility, piled foundation and geometrical imperfections. For this purpose, a fixed offshore jacket-type platform, typical of the North Sea, is considered. The structure is modelled using the non-linear finite-element analysis (NLFEA) software suite - Abaqus (Abaqus Documentation, version 6.12 (Abaqus, 2012)). The loads applied at the platform include functional loads, buoyancy and typical environmental loads including wind and wave. The joints are modelled using the centre-to-centre approach with flexible joints, the face-to-face approach with rigid joints and a hybrid shell-to-beam approach. The piled foundation is modelled with soil-structure interaction using the implicit approach and compared with the fully fixed boundary conditions. The imperfections are introduced in the jacket compression legs to study the effect of the reduced leg buckling strength on the jacket behaviour.

\section{NLFEA model}

\subsection{Model geometry and material}

The structure analysed in this paper is a typical basic jackettype offshore structure shown in Figure 1. The installation consists of a four-legged X-braced steel jacket substructure with five horizontal frames supporting a topside model and standing in a water depth of $125 \mathrm{~m}$. The jacket frame consists of four bays, which are named as the bottom, middle-bottom, middle-top and top bays. The bottom and middle-bottom bays are $35.2 \mathrm{~m}$ high, while the middle-top and top bays are $30.2 \mathrm{~m}$ high. The model axes $X, Y$ and $Z$ represented the east, north and vertical directions. This orientation is used for description of the directions of environmental loads. Additionally, 
Fidelity of computational modelling of offshore jacket platforms

Vilnay, Sivickij, Watters, Doerich-Stavridis and Chernin

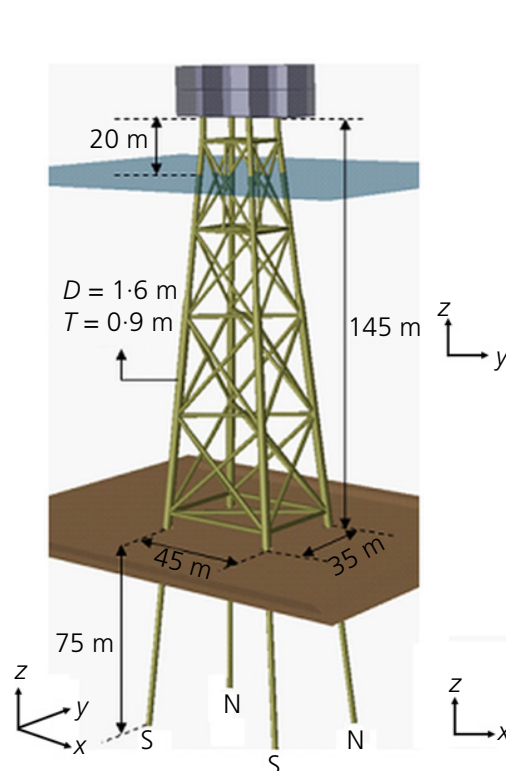

(a)

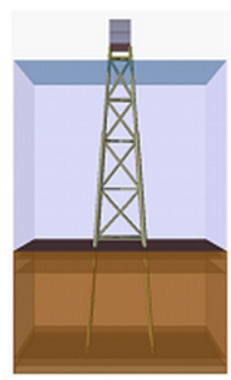

(b)

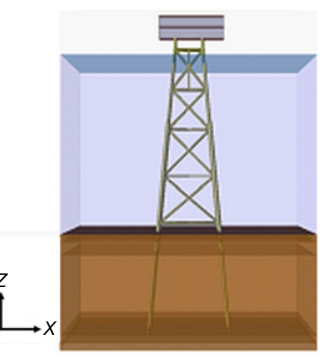

(c)
Figure 1. NLFEA model of jacket platform: (a) isometric view; view from (b) $X$ and (c) $Y$ directions

the jacket legs are named in accordance with the orientation, north-west (NW), north-east (NE), south-west (SW) and south-east (SE) leg, as shown in Figure 1.

The topside was primarily constructed using I-beams with heavier bottom flange and steel plates, whereas the jacket using steel tubular members is typical of the platform type. Therefore, the topside was modelled using beam and shell elements in all platform models analysed in this study. The density of steel was assumed equal to $7850 \mathrm{~kg} / \mathrm{m}^{3}$, Young's modulus to $210 \mathrm{GPa}$ and Poisson's ratio to $0 \cdot 3$. Plasticity of the steel material was accounted for using the von Mises criterion with isotropic hardening, with yield stress set to $355 \mathrm{MPa}$.

\subsection{Modelling of loads}

Offshore jacket-type structures are generally subjected to operational and environmental loads. Operational loads typically include the dead (or functional) load generated from the selfweight of the jacket and equipment, live loads from utilisation of the topside (equipment, living modules) and also buoyancy loads. Buoyancy is calculated in accordance to accepted practice (Douglas, 2011) based on the weight of the fluid displaced by the structure, meaning that larger members create more fluid displacement. The environmental loads are comprised of the wind and wave loads. Modern offshore fixed installations are commonly designed to resist the 1-year operating load and 100 -year environmental storm load. The latter is attributable to the combined wave and wind loads that occur during the storm which is characterised by a return period of 100 years (Nelson, 2003). The wave load consists of the transverse fluid drag and inertia, which are calculated based on the Morison equation (ISO 19902 (BS EN ISO 19902:2007 (BSI, 2007))). As a result, the wave load on each jacket member depends on its diameter, location in the frame and orientation relative to the wave direction. Partial factors of safety are applied to the loads in compliance with ISO 19902.

The gravity and buoyancy loads were applied to the platform model gradually, over several increments. The environmental loads corresponded to the North Sea conditions. The wind load was applied to exposed surfaces of the platform above the sea level, while the wave load was applied to submerged jacket members. This effectively generated a push-over effect on the structure, where high overturning moments and shear forces were generated at the base of the rig. To evaluate how the jacket structure behaved under the environmental loads applied in different directions and find out which direction was the most critical, eight analysis cases were carried out: north, north-east, east, south-east, south, south-west, west and northwest (see Figure 2). The name of each analysis case indicates the direction of the environmental loads. It is important to note that the north, south, east or west direction are called the end-on directions, while the north-east, south-west, north-west or south-east directions are called broadside directions.

The submerged part of the jacket is always colonised by marine growth (or biofouling), which consists of a variety of species depending on the location, depth and configuration of the structure. The marine growth has several effects on the loads applied to the structure. It increases structural dimensions, displaced volume, structural weight, hydrodynamic added mass, drag forces and flow instability around the jacket (Jusoh and Wolfram, 1996). In this study, the marine growth was assumed to develop only above $94 \mathrm{~m}$ from the seabed. At $100 \mathrm{~m}$ above the seabed the marine growth reached $50 \mathrm{~mm}$ and at $125 \mathrm{~m}$ above the seabed to $100 \mathrm{~mm}$. These values are

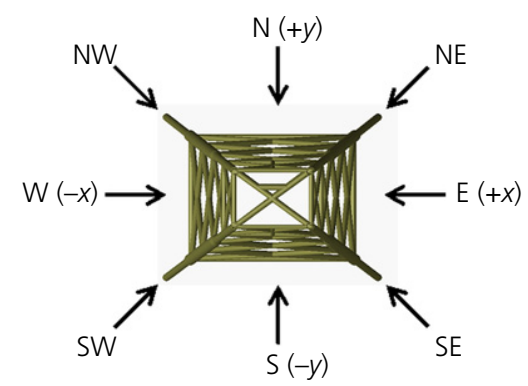

Figure 2. Directions of environmental loads 
typical of ageing North Sea offshore structures. A linear increase in the marine growth was assumed between the heights specified.

\subsection{Modelling of joints}

The joints in the jacket were modelled using three different methods. The first method was based on the face-to-face approach for modelling brace members, see Figure 3(a). The points, where the braces were connected to legs, were dictated by true cross-sections of the legs (see Figure 3(b)). Therefore, the joints were offset and did not influence each other directly. The connections between the braces and the legs were introduced into the model using rigid elements, which were tied together at the connection with the leg. Hence, any local deformation was prevented, and joint flexibility was disregarded. All members of the jacket were modelled using beam elements.

In the second method, the centre-to-centre approach was applied for modelling brace members. All braces in one joint were connected to the leg at the same node located at the centre of the joint, as demonstrated in Figure 3(c). This made the braces longer by leg radii on both ends and thus more flexible, simulating the effect of joint flexibility implicitly. All members of the jacket were also modelled using beam elements.

The third method employed a hybrid approach which was based on detailed modelling of one jacket leg using shell elements, as shown in Figure 4. The rest of the jacked was modelled using beam elements and the face-to-face approach. As a result, the effect of joint flexibility was explicitly considered in the joints of the shell leg. In the model, the beam elements were connected to the shell elements by tying the degrees of freedom of the end nodes. It should be noted that this approach was applied here due to the reduced computational cost of the NLFEA analysis compared with modelling whole jacket using shell elements. In order to decide which

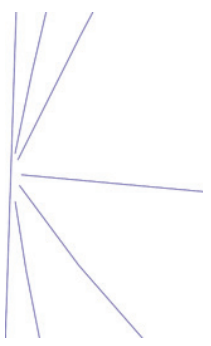

(a)

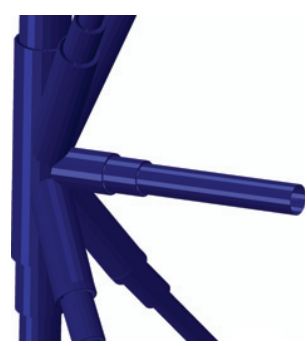

(b)

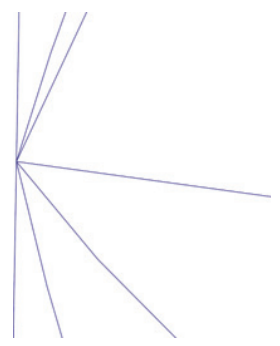

(c)
Figure 3. Face-to-face approach for modelling braces: (a) beam element representation, (b) true cross-section representation, (c) centre-to-centre approach for modelling braces

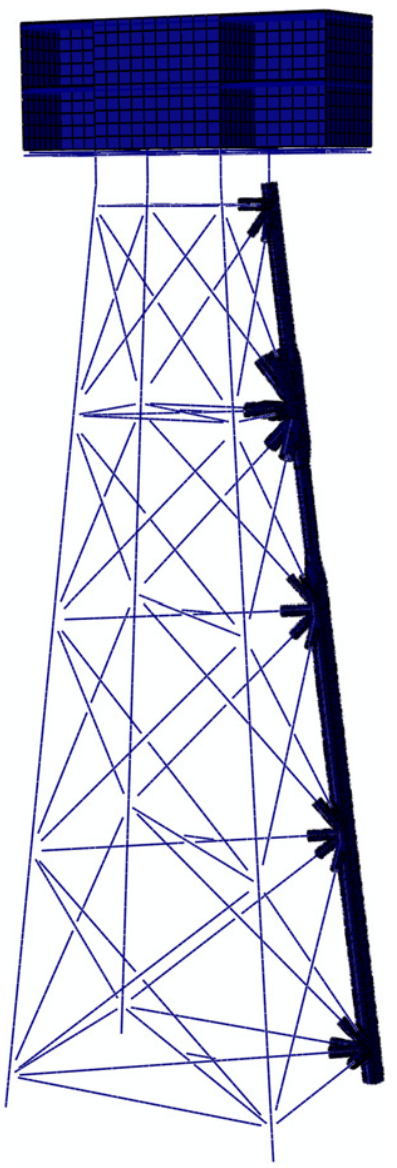

Figure 4. Hybrid shell-to-beam model. The north-east leg is modelled using shell elements, while the rest of the jacked using beam elements

loading direction is the most critical and which leg to model with shell elements, eight analyses of the platform loaded in the directions stated in Section 2.2 were run. These analyses determined that the south-west loading direction is the most critical and therefore the north-east leg is to be modelled with shell elements due to the high stresses that develop in the leg.

\subsection{Modelling of piled foundation}

To investigate the effect of piled foundation on the behaviour of the jacket rig, two models were analysed and compared. In one model, a piled foundation was explicitly incorporated (e.g. see Figure 5). The jacket was attached to the seabed by four piles driven $75 \mathrm{~m}$ deep into the soil and extended above the mud-line into the main legs of the platform. The soil was implicitly modelled using springs distributed along the steel piles. Separate soil layers were represented by springs with corresponding equivalent stiffness. This study considered a case where piles are driven into soil consisting of three sand 


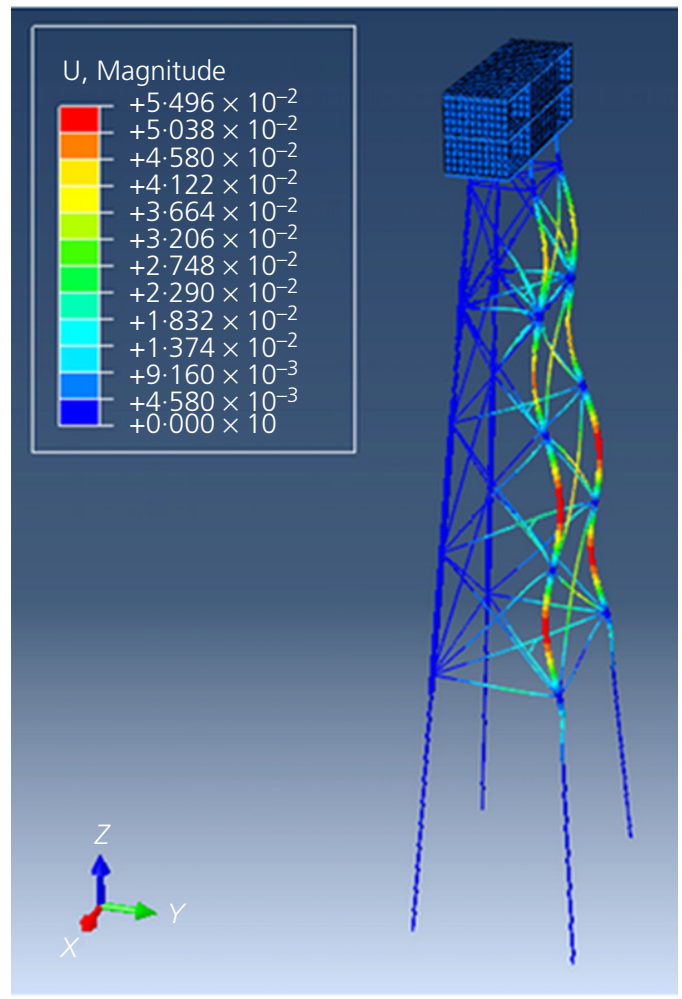

(a)

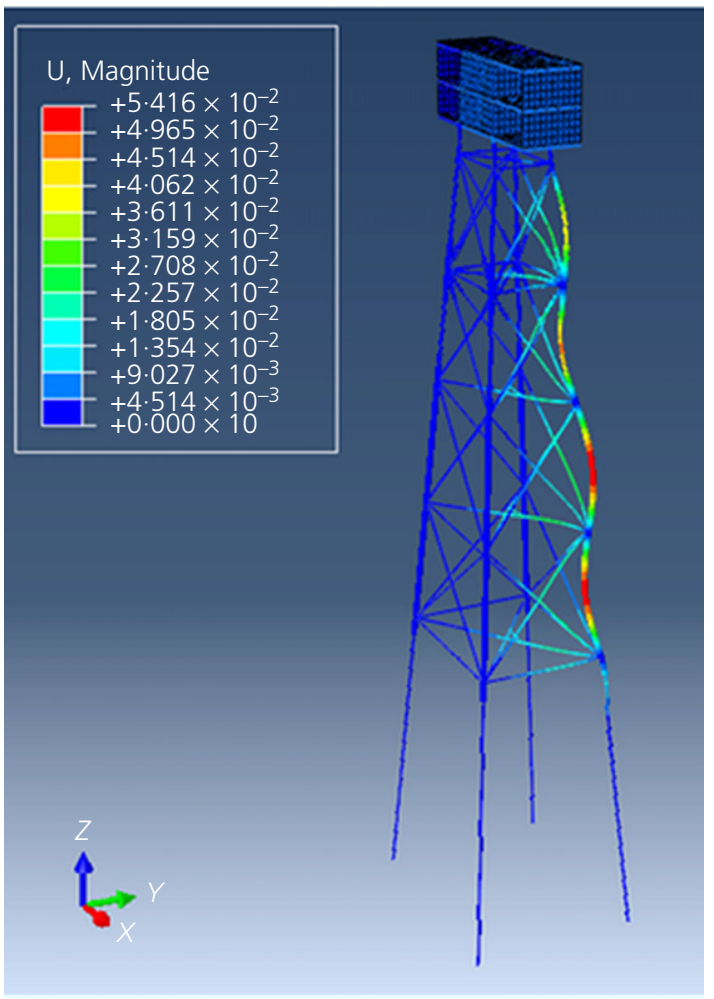

(b)

Figure 5. Models with geometrical imperfection in (a) both north legs and (b) north-east leg. In the legend, ' $U$ ' stands for displacement. The deformation scale factor of 50 was applied to the models

layers between $0 \mathrm{~m}$ and $-5.5 \mathrm{~m}$ below the mud-line and two clay layers between $-5 \cdot 5$ and $-70 \mathrm{~m}$ below the mud-line. The pile tip was positioned in the additional sand layer that started at $-70 \mathrm{~m}$ and extended to the depth of $-100 \mathrm{~m}$. The soil layers were characterised using the relationships for the endbearing resistance against displacement at the pile tip, for the shear transfer (skin friction) against pile displacement and for the lateral soil resistance against displacement, as per ISO 19902. These constitutive relationships were used for modelling the behaviour of springs. The piles were modelled using beam elements with circular cross-sections. The behaviour of the platform with piled foundation was compared with the platform fixed to the seabed.

\subsection{Modelling of imperfections}

The influence of imperfections on the jacket behaviour was examined using the model with piled foundations. The geometrical imperfections were introduced directly into the model by changing the shape of the legs only, as buckling of a leg is considered more critical than buckling of a brace. It is a common practice within the offshore industry to assume the equivalent imperfection $\left(w_{\mathrm{i}}\right)$ at the mid-span as equal to
$0 \cdot 15 \%$ of the element length $(l)$. Therefore, a simplified version of Equation 1, given below, was used for evaluation of the imperfections

2. $w_{\mathrm{i}}=0 \cdot 0015 l$

For the two bottom bays with a leg length of $35234.7 \mathrm{~mm}$ and the two top bays with a leg length of $30201.2 \mathrm{~mm}$, Equation 2 yields the imperfection values of 52.85 and $45.3 \mathrm{~mm}$, respectively. These geometrical imperfections were introduced into the models in two stages. At the first stage, the shape of the leg with imperfections was obtained by application of equivalent forces to the leg at the middle of each bay. The leg was also restrained by simple horizontal supports at each joint to prevent the influence of jacket deformation on the 'imperfect' leg shape. Each equivalent force was increased in value until a desirable imperfection developed. The 'imperfect' shape was recorded, and the forces and supports were removed. At the second stage, the operational and environmental loads were applied on the 'imperfect' jacket platform, and the effect of imperfection examined. 
Several trial analyses showed that imperfections can either decrease or increase the ultimate strength of the platform. To consider the worst-case scenario, the direction of each force and thus the imperfection was selected based on the failure modes of the model without imperfections. As a result, the imperfections increased the deformation of the jacket under the operational and environmental loads and caused maximum damage to the load-carrying capacity of the platform.

The imperfections were introduced into both compression legs in the end-on load cases and into the compression leg in the broadside load cases. Figure 5 depicts two models with imperfection introduced into (i) both north legs and (ii) the north-east leg. The model in Figure 5(a) is designated for the end-on south loading, while in Figure 5(b) for the broadside South-west loading. As can be seen, the imperfection is introduced in each leg in every bay of the frame in opposite direction, which creates a shape similar to a buckling mode of the leg.

\subsection{Analysis procedure}

It is common practice to determine the ultimate capacity of the jacket rig using static push-over analysis. This type of analysis accounts for the non-linear response in an incremental-iterative way. For a realistic representation of offshore platform behaviour, the analysis was conducted in several steps. The arrangement of steps is significant, since it controls the sequential chain of events during the analysis. The steps included the consecutive application of the gravity, buoyancy and service loads, followed by the application of the environmental loads, which were gradually increased by the load proportionality factor (LPF) until the structure reached its ultimate resistance load (ultimate strength) and failed. The ultimate resistance $\left(R_{\mathrm{ult}}\right)$ of the structure at the state of collapse can be represented by the following relationship (Lloyd and Clawson, 1983)

3. $R_{\mathrm{ult}}=\lambda_{\text {ult }} E$

where $\lambda_{\text {ult }}$ is the LPF at collapse and $E$ is the unfactored (characteristic) global environmental actions.

An elastic response was observed in the platform subjected to the operational and initial environmental loads. However, the increasing environmental loads pushed-over the structure beyond the elastic response. The non-linear behaviour of the platform was analysed using the modified Riks method (Abaqus Documentation, version 6.12 (Abaqus, 2012)), which allowed to determine the ultimate load-carrying capacity and the mode of failure.

\section{Analyses results and discussion}

\subsection{Behaviour of platform}

Two sets of computational simulations were carried out for the rigid and flexible joint models subjected to eight load cases (four end-on and four broadside load cases). In the first set, the models were analysed without and with piles, while in the second set with piles. The results of the computational simulations containing the load-carrying capacity (i.e. LPF at the first yielding and maximum LPF) and the stiffness (represented by the LPF divided by the maximum deformation, $\delta$, in the jacket) of the platform are presented in Tables 1 and 2 for the rigid and flexible joint models, respectively. The data in the tables below is analysed and discussed in the following sections.

The results of non-linear static push-over analyses of the platform indicated that, in general, the collapse of the jacket structure was governed by the failure (buckling) of bracing elements in the space frame. This conclusion is supported by the findings in Skallerud and Amdahl (2002). The behaviour of the jacket subjected to static loads was typical of a space truss. As the structure reached its ultimate load, the behaviour was dominated by axial forces in the braces. The initial response of the jacket was linear until buckling of the first brace took place. This caused a significant instantaneous drop in the global load-carrying capacity. The drop was so dramatic that dynamic spring-back occurred, which was followed by load redistribution between adjacent members and recovery of platform-carrying capacity and stiffness. On further increase of the loads, more braces buckled and similar spring-back occurred again. This process continued until structure eventually reached its ultimate strength followed by complete failure.

The failure mode of the jacket depended on the direction of the applied environmental loads. When the platform was subjected to an end-on loading, it underwent buckling failure of the horizontal and diagonal braces within its supporting frame. Figure 6 illustrates the failure modes of braces in the jacket subjected to the end-on west loading.

When the environmental loading was applied from a broadside direction, three front legs carried tension forces, while only the back leg carried compression forces. Therefore, it was initially expected that buckling of the entire compression leg would occur before any other failure modes. However, the large wall thickness of bottom section of jacket legs resulted in high axial stiffness of the compression leg, while braces had smaller sections and buckled first. Figure 7 presents the failure modes for the broadside south-west loading, where the highest deformations occurred in the compression leg and in the compression braces of the middle-top bay.

The comparison of the load cases indicates that in the end-on load case (Figure 6), compression braces failed by buckling in all three bottom bays, while in the broadside load case (Figure 7), the compression braces buckled only in the middle-top bay of the frame. In both load cases, buckling 
Table 1. Sustained loads (in terms of LPF) and stiffness of the rigid joint model without and with piles under different load cases

\begin{tabular}{|c|c|c|c|c|c|c|}
\hline \multirow[b]{2}{*}{ Load case } & \multicolumn{2}{|c|}{ LPF at first yielding } & \multicolumn{2}{|c|}{ Maximum LPF } & \multicolumn{2}{|c|}{ Stiffness (LPF/ $\delta$ ) } \\
\hline & No piles & Piles & No piles & Piles & No piles & Piles \\
\hline North & 3.81 & $3 \cdot 51$ & $4 \cdot 85$ & 4.48 & $12 \cdot 71$ & $6 \cdot 16$ \\
\hline North-east & $5 \cdot 58$ & 5.05 & $6 \cdot 44$ & $5 \cdot 99$ & $15 \cdot 91$ & $7 \cdot 67$ \\
\hline East & $5 \cdot 30$ & 4.68 & $6 \cdot 85$ & 6.04 & 21.94 & $11 \cdot 25$ \\
\hline South-east & $5 \cdot 53$ & 5.01 & $6 \cdot 35$ & 5.82 & $15 \cdot 95$ & $7 \cdot 51$ \\
\hline South & 3.89 & $3 \cdot 49$ & 4.66 & $4 \cdot 28$ & $12 \cdot 39$ & 5.84 \\
\hline South-west & $5 \cdot 48$ & 4.92 & $6 \cdot 40$ & $5 \cdot 80$ & $15 \cdot 55$ & $7 \cdot 38$ \\
\hline West & $5 \cdot 06$ & $4 \cdot 52$ & $6 \cdot 66$ & $5 \cdot 98$ & $21 \cdot 55$ & $10 \cdot 80$ \\
\hline North-west & $5 \cdot 60$ & $5 \cdot 10$ & $6 \cdot 58$ & $6 \cdot 00$ & $16 \cdot 14$ & $7 \cdot 55$ \\
\hline
\end{tabular}

Table 2. Sustained loads (in terms of LPF) and stiffness of the flexible joint model without and with piles under different load cases

\begin{tabular}{|c|c|c|c|c|c|c|}
\hline \multirow[b]{2}{*}{ Load case } & \multicolumn{2}{|c|}{ First yield LPF } & \multicolumn{2}{|c|}{ Maximum LPF } & \multicolumn{2}{|c|}{ Stiffness (LPF/ $\delta$ ) } \\
\hline & No piles & Piles & No piles & Piles & No piles & Piles \\
\hline North & 3.45 & 3.43 & 4.06 & $4 \cdot 24$ & $11 \cdot 12$ & 6.00 \\
\hline North-east & 4.92 & $4 \cdot 86$ & $5 \cdot 76$ & $5 \cdot 74$ & 13.49 & $7 \cdot 26$ \\
\hline East & $4 \cdot 62$ & 4.55 & 6.04 & $5 \cdot 87$ & 18.65 & $10 \cdot 73$ \\
\hline South-east & 4.90 & $4 \cdot 82$ & $5 \cdot 59$ & $5 \cdot 56$ & $13 \cdot 34$ & $7 \cdot 10$ \\
\hline South & 3.45 & $3 \cdot 40$ & 4.08 & 4.07 & $10 \cdot 31$ & $5 \cdot 70$ \\
\hline South-west & 4.90 & $4 \cdot 82$ & 5.65 & $5 \cdot 57$ & $15 \cdot 55$ & 6.98 \\
\hline West & $4 \cdot 56$ & $4 \cdot 50$ & $5 \cdot 85$ & $5 \cdot 74$ & $17 \cdot 93$ & $10 \cdot 34$ \\
\hline North-west & $5 \cdot 14$ & 5.08 & $5 \cdot 79$ & $5 \cdot 79$ & $13 \cdot 55$ & $7 \cdot 28$ \\
\hline
\end{tabular}

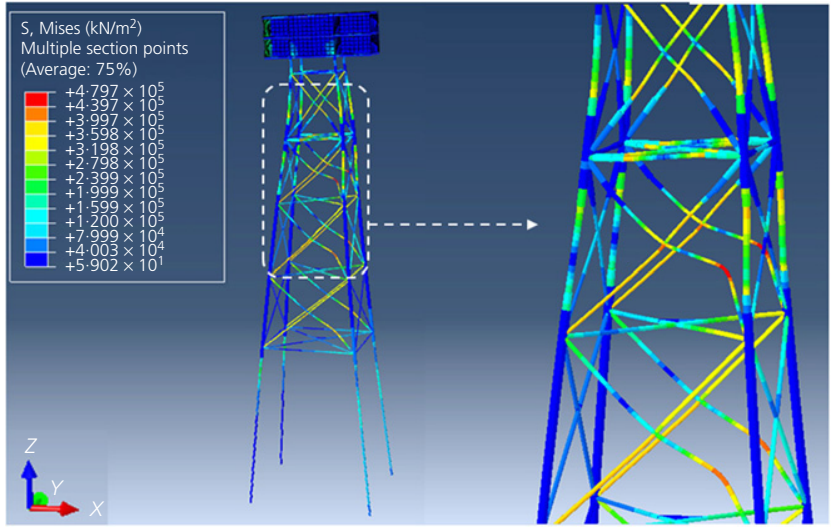

Figure 6. Mode of failure of flexible joint model with piled foundation subjected to end-on west loading. In the legend, ' $S$ ' stands for stress. The deformation scale factor of 50 was applied to the models

failure occurred first in the middle-top bay, where the stiff lower leg section connected to a less stiff upper leg section.

\subsection{Effect of joint flexibility}

The effect of joint flexibility introduced using the face-to-face approach was initially considered by comparing the data in

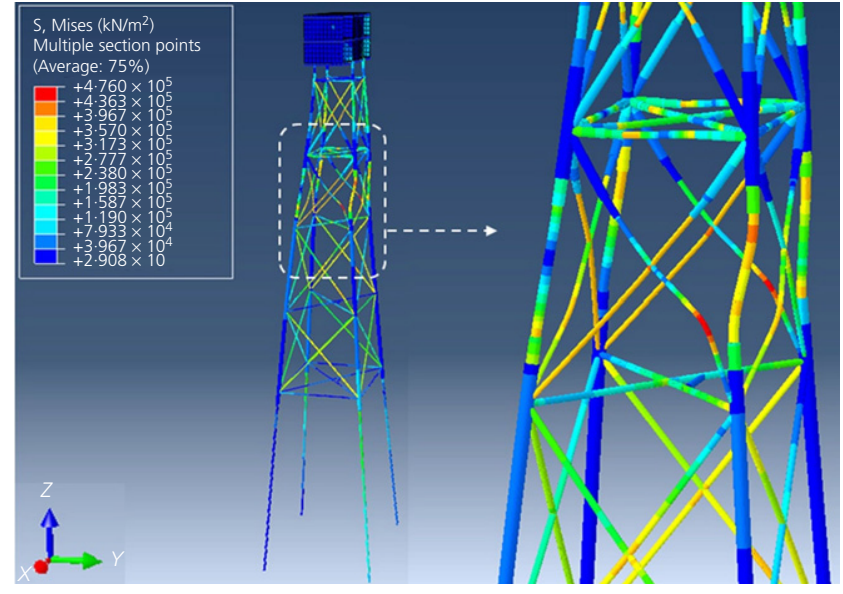

Figure 7. Mode of failure of flexible joint model with piled foundation subjected to broadside south-west loading. In the legend, 'S' stands for stress. The deformation scale factor of 50 was applied to the models

Tables 1 and 2. The results of the comparison are presented in Table 3 separately for the models without and with piled foundation as percentile differences between the rigid and flexible joint models in the first yield and maximum sustained loads 
Table 3. Effect of joint flexibility of sustained load and stiffness of the platform under different load cases

\begin{tabular}{|c|c|c|c|c|c|c|}
\hline \multirow[b]{3}{*}{ Load case } & \multicolumn{6}{|c|}{ Difference between rigid and flexible joint models: \% } \\
\hline & \multicolumn{3}{|c|}{ Models without piles } & \multicolumn{3}{|c|}{ Models with piles } \\
\hline & First yield LPF & Maximum LPF & Stiffness & First yield LPF & Maximum LPF & Stiffness \\
\hline North & $9 \cdot 45$ & $16 \cdot 28$ & $12 \cdot 55$ & $2 \cdot 28$ & $5 \cdot 31$ & $2 \cdot 66$ \\
\hline North-east & $11 \cdot 83$ & $10 \cdot 49$ & $15 \cdot 23$ & $3 \cdot 76$ & $4 \cdot 28$ & $5 \cdot 44$ \\
\hline East & $12 \cdot 83$ & $11 \cdot 89$ & 14.98 & 2.78 & $2 \cdot 84$ & $4 \cdot 64$ \\
\hline South-east & $11 \cdot 39$ & $12 \cdot 01$ & $16 \cdot 38$ & $3 \cdot 79$ & $4 \cdot 40$ & $5 \cdot 35$ \\
\hline South & $11 \cdot 31$ & $12 \cdot 45$ & $16 \cdot 80$ & $2 \cdot 58$ & 4.90 & $2 \cdot 41$ \\
\hline South-west & $10 \cdot 58$ & $11 \cdot 71$ & 0.00 & $2 \cdot 03$ & 3.96 & $5 \cdot 49$ \\
\hline West & $9 \cdot 88$ & $12 \cdot 20$ & $16 \cdot 78$ & 0.44 & 3.97 & $4 \cdot 27$ \\
\hline North-west & $8 \cdot 21$ & 11.98 & 16.03 & 0.39 & 3.52 & $3 \cdot 61$ \\
\hline Average & $10 \cdot 69$ & $12 \cdot 37$ & $13 \cdot 60$ & $2 \cdot 26$ & $4 \cdot 15$ & $4 \cdot 23$ \\
\hline
\end{tabular}

and stiffness. For the model without piles, the incorporation of flexible joints into the platform model led to the $10.69 \%$ reduction in the first yielding load, the $12.37 \%$ reduction in the platform strength and the $13 \cdot 6 \%$ reduction in the platform stiffness, on average. As a result, the platform strength and stiffness were more sensitive to the effect of joint flexibility, especially for loads in certain directions. The models with piled foundations were much less sensitive to the flexibility of joints. The effect of joint flexibility was reduced by nearly 5 times, on average, for the first yielding load and by 3 times for the strength and stiffness.

For the three types of joints considered (i.e. rigid, flexible and hybrid), analyses were conducted using fixed boundary conditions. The three platforms were loaded by the environmental loads in the most critical south-west direction. Figure 8 shows the platforms at the moment of failure. The locations of material yielding are highlighted in red. Note that Figures 8(a) and 8 (b) are rendered, showing jacket member cross-sections to scale. The comparison of the models with rigid and flexible joints showed that yielding occurred in similar locations; however, smaller yielding zones developed in the rigid joint model (see Figures 8(a) and 8(b)). Additional braces also yielded in the middle-top and top bays of the jacket in the flexible joint model. This happened due to the braces in the rigid joint model being shorter and therefore stiffer and able to transfer higher loads without yielding. In the hybrid model, the second joint of the north-east shell leg from the seabed did not yield, while the yielding zone in the first joint was much smaller than in the other two models (see Figure 8(c)). The comparison between the rigid joint and hybrid models demonstrated that the brace connected to the north-east compression leg in the middle-top bay of the hybrid model did not yield, but some other braces in the middle-top and top bays yielded to a greater extent. In all models, the north-west and southwest legs yielded at the supports, where the yielding zones were the largest in the hybrid model. The south-east leg yielded

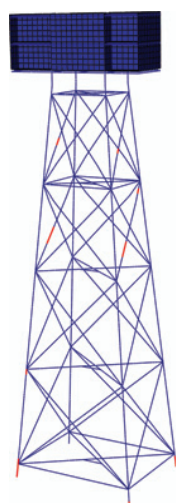

(a)

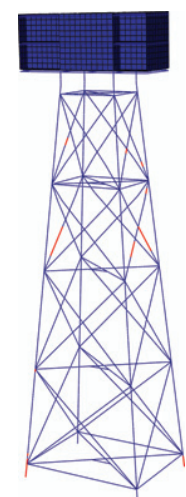

(b)

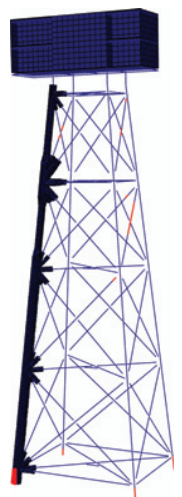

(c)
Figure 8. Yielding in the jacket structure with (a) rigid, (b) flexible and (c) hybrid joints, subjected to broadside south-west loading

only in the hybrid model. This behaviour indicates that the redistribution of loads from the north-east shell leg to the other beam legs occurred in the hybrid jacket due to higher shell leg flexibility. The comparison between the flexible joint and hybrid models suggests that these methods result in a different response of the jacket to the applied loads.

Figure 9 shows the LPF against maximum global deformation in the jacket for the three considered models (without piled foundation) loaded in the broadside south-west direction. The global deformation represents the cumulative displacement of the whole jacket composed from the displacements of individual components. The highest structural capacity was demonstrated by the rigid joint model. Both the rigid and flexible joint models exhibited ductile behaviour, while the hybrid model behaved in a brittle manner. All the models behaved in a similar way until the point of first yield. The flexible joint model yielded at a LPF of 4.48 and the maximum jacket deformation of $0.29 \mathrm{~m}$, while the rigid joint and hybrid models 


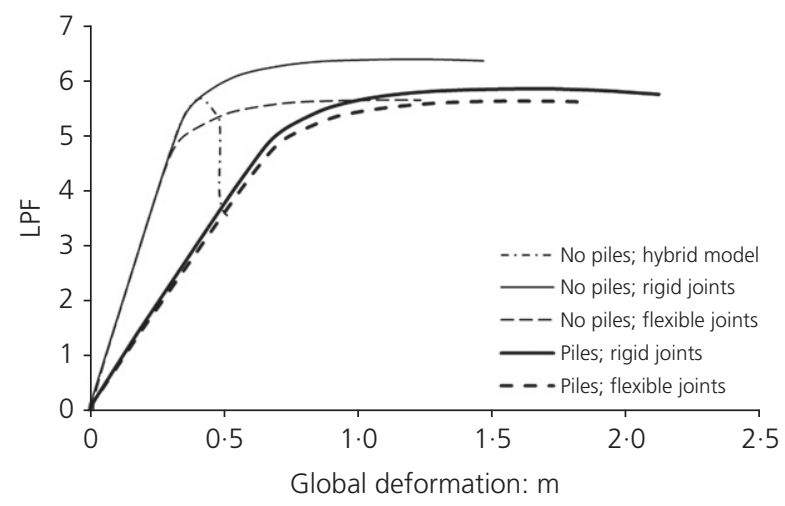

Figure 9. LPF plotted against maximum global deformation in the rigid joint, flexible joint and hybrid models subjected to broadside south-west loading

yielded at a slightly higher LPF of $5 \cdot 27$ and a deformation of $0.35 \mathrm{~m}$. The stiffness of all three models was similar. As the load increased further, the analysed models responded in a non-linear manner due to the formation of plastic hinges and buckling of braces, which resulted in the gradual reduction of stiffness and load redistribution. The flexible joint model lost its stiffness faster than the other two. The hybrid model failed by buckling of entire shell leg at a LPF of 5.68 and a maximum jacket deformation of $0.42 \mathrm{~m}$, after which a period of unloading occurred. The rigid joint model was able to carry the maximum load of LPF equal to 6.40 with a corresponding deformation of $1.18 \mathrm{~m}$. Further, small reduction of the LPF occurred with the increase in the deformation but without a distinct limit point as in the hybrid model case. The flexible joint model behaved similarly to the rigid joint model but showed lower carrying capacity with the LPF reaching 5.65 at the deformation of $1.24 \mathrm{~m}$. Therefore, the incorporation of the flexible joints led to the $11 \cdot 7 \%$ reduction in the structural strength of the platform.

It is important to note that both the flexible joint and hybrid models demonstrated similar maximum load-carrying capacity. The hybrid model underwent much less deformation before failure than the other models. This brittle behaviour was the result of the jacket structural configuration. The compression leg and connected joints were modelled using shell elements, which allowed capturing the accumulative effects of localised yielding and localised shell buckling in both the leg and braces. As a result, the joints were flexible and the compression leg was less restrained against global buckling. The analysis of the curves in Figure 9 suggests that the rigid joint model could overestimate the strength of the jacket, while both the rigid and flexible joint models could significantly overestimate the deformability of the jacket. The latter conclusion is supported by the findings in Mirtaheri (2009).
The effect of joint flexibility on the shear force at the jacket base was also investigated. The base shear force (SF) was calculated at the first yielding of the jacket for each load case using the following expression

4. $\mathrm{SF}=\sqrt{\left(\sum \mathrm{SF}_{x}\right)^{2}+\left(\sum \mathrm{SF}_{y}\right)^{2}}$

where $\sum \mathrm{SF}_{x(y)}$ is the sum of the shear forces at the piled foundation in the $X$ (or $Y$ ) direction. Since only the base shear force generated by the environmental loading was of interest, the values of the base shear generated by the operational (dead, live and buoyancy) loads were disregarded. Table 4 presents the maximum base shear forces for the rigid and flexible joint models with piled foundations subjected to eight loading cases. As can be observed, the broadside loading cases resulted in higher base shear force (by up to $22 \%$ ) than the end-on loading cases in both types of models. Also, the base shear force was higher (by up to $5 \%$ ) in the rigid joint model than in the flexible joint model. The maximum base shear force in the hybrid model loaded in the broadside south-west direction was $172.6 \mathrm{MN}$, which is smaller than the maximum base shear force in the rigid joint by $17 \cdot 6 \%$.

\subsection{Effect of piled foundation}

The effect of piled foundation is initially considered by comparing the data in Tables 1 and 2. The results of the comparison are presented in Table 5 separately for the rigid and flexible joint models as percentile differences in the first yield and maximum sustained loads and stiffness. It is evident that the incorporation of piled foundation into the rigid joint model resulted in the $9.82 \%$ reduction of the first yielding load, the $9.8 \%$ reduction of the strength and the $51.67 \%$ reduction of the stiffness of the platform, on average. As a result, the stiffness of the platform was most significantly affected by the base movement and rotation introduced by the piles, especially in certain loading directions. The first yielding load and strength of the flexible joint model were much less

Table 4. Maximum base shear force for rigid and flexible joint models with piled foundations

\begin{tabular}{lccc}
\multicolumn{3}{c}{ Base shear force: MN } \\
\cline { 2 - 3 } $\begin{array}{l}\text { Loading } \\
\text { case }\end{array}$ & $\begin{array}{c}\text { Rigid joint } \\
\text { model }\end{array}$ & $\begin{array}{c}\text { Flexible joint } \\
\text { model }\end{array}$ & \\
\hline North & 175.34 & 167.23 & 4.6 \\
North-east & 210.96 & 202.46 & 4.0 \\
East & 189.53 & 184.70 & 2.5 \\
South-east & 208.11 & 199.60 & 4.1 \\
South & 173.87 & 165.69 & 4.7 \\
South-west & 209.49 & 201.43 & 3.8 \\
West & 190.73 & 184.08 & 3.5 \\
North-west & 211.81 & 204.08 & 3.6 \\
\hline
\end{tabular}


Table 5. Effect of piled foundation on sustained load and stiffness of the platform under different load cases

\begin{tabular}{|c|c|c|c|c|c|c|}
\hline \multirow[b]{3}{*}{ Load case } & \multicolumn{6}{|c|}{ Difference between models without and with piles: \% } \\
\hline & \multicolumn{3}{|c|}{ Rigid joint model } & \multicolumn{3}{|c|}{ Flexible joint model } \\
\hline & First yield LPF & Maximum LPF & Stiffness & First yield LPF & Maximum LPF & Stiffness \\
\hline North & $7 \cdot 87$ & $7 \cdot 58$ & $51 \cdot 53$ & 0.58 & $-4 \cdot 53$ & $46 \cdot 05$ \\
\hline North-east & $9 \cdot 50$ & $6 \cdot 89$ & $51 \cdot 78$ & $1 \cdot 22$ & 0.43 & $46 \cdot 21$ \\
\hline East & $11 \cdot 70$ & $11 \cdot 78$ & $48 \cdot 70$ & 1.52 & $2 \cdot 72$ & $42 \cdot 46$ \\
\hline South-east & $9 \cdot 40$ & $8 \cdot 37$ & 52.95 & 1.63 & 0.45 & $46 \cdot 74$ \\
\hline South & $10 \cdot 28$ & $8 \cdot 14$ & $52 \cdot 85$ & 1.45 & 0.22 & 44.69 \\
\hline South-west & $10 \cdot 22$ & $9 \cdot 29$ & $52 \cdot 50$ & 1.63 & $1 \cdot 33$ & $55 \cdot 11$ \\
\hline West & $10 \cdot 67$ & $10 \cdot 32$ & $49 \cdot 89$ & $1 \cdot 32$ & 1.92 & $42 \cdot 35$ \\
\hline North-west & 8.93 & $8 \cdot 79$ & $53 \cdot 20$ & $1 \cdot 17$ & 0.03 & $46 \cdot 28$ \\
\hline Average & $9 \cdot 82$ & 8.90 & $51 \cdot 67$ & $1 \cdot 31$ & $0 \cdot 32$ & $46 \cdot 24$ \\
\hline
\end{tabular}

sensitive to the presence of the piled foundation; however, the reduction of stiffness was still significant.

Figures 9 and 10 present load-deformation curves obtained from the push-over analyses of the rigid and flexible joint models with and without piles subjected to environmental loads applied from the broadside south-west and end-on west directions. The application of the operational loads resulted in insignificant global deformation of the platform, which was in the linear range of structural behaviour. Therefore, the load-deformation curves in Figures 9 and 10 only consider data obtained from the application of the environmental loads. It is evident that the piled foundation and joint flexibility have similar effects on the platform in both load cases. The incorporation of piled foundation resulted in the severe reduction of structural stiffness regardless of the joint modelling approach. The reduction of the first yielding load and especially of the platform strength was only significant in the rigid joint model. These observations support the data in Tables 1,2 and 5.

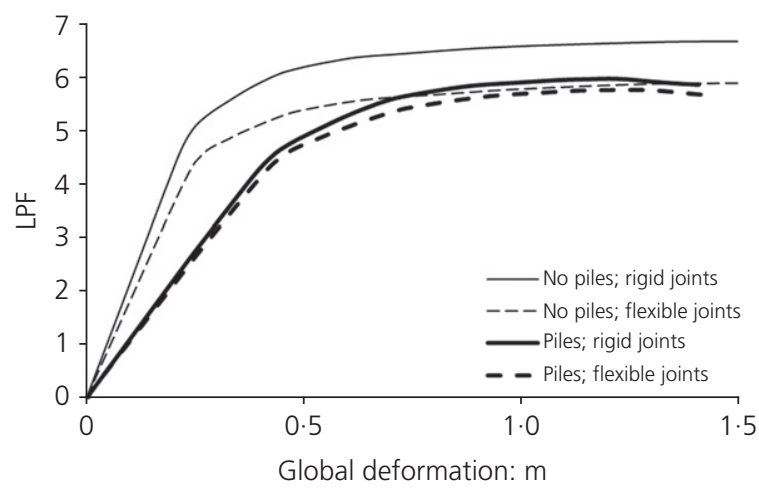

Figure 10. LPF plotted against maximum global deformation in the rigid and flexible joint models with and without piled foundation subjected to end-on west loading

\subsection{Effect of geometrical imperfections}

The effect of geometrical imperfections was investigated by comparing models with imperfections against models without imperfections (i.e. perfect model). The effect of joint flexibility was also considered. Figure 11 demonstrates the deformed shapes of two platforms subjected to (i) end-on south and (ii) broadside south-west loadings with imperfections in compression legs, as shown in Figure 5. The state captured in Figure 11 corresponds to the first converged increment after the application of the environmental load. As can be observed in both cases, the geometrical imperfections had the highest impact on the compression leg in the bottom bay, because this leg segment was long (relative to the middle-top and top bay segments) and subjected to higher shear and compression forces than the segments above. Bending of each compression leg caused rotation of joints, especially the bottom one, and bending of connected braces and the supporting pile.

Figures 12 and 13 present the load-deformation for the two models shown in Figures 5 and 11. The models had piled foundations and rigid or flexible joints. As can be seen in the figures, the imperfection introduced initial deformation in the jacket elements shifting the beginning of the load-deformation curve. This phenomenon occurred because the imperfections contributed to the net deformation of the jacket. The initial deformation in the platform with imperfections in both north legs subjected to the end-on south loading (Figure 12) was $2.25(=0.173 \mathrm{~m} / 0.077 \mathrm{~m})$ times larger than in the platform with imperfection in the north-east leg subjected to the broadside south-west loading (Figure 13). The initial deformation in all models with imperfections was recovered through smaller deformation rate under loading, and the load-deformation curves joined with those of the models without imperfections after the first yielding occurred and before the ultimate load was reached. The presence of imperfections in compression legs did not affect the initial stiffness, the first yield load or the platform strength. The platforms behaved in a similar way 
Engineering and Computational Mechanics Volume 172 Issue EM2
Fidelity of computational modelling of

offshore jacket platforms

Vilnay, Sivickij, Watters, Doerich-Stavridis and

Chernin

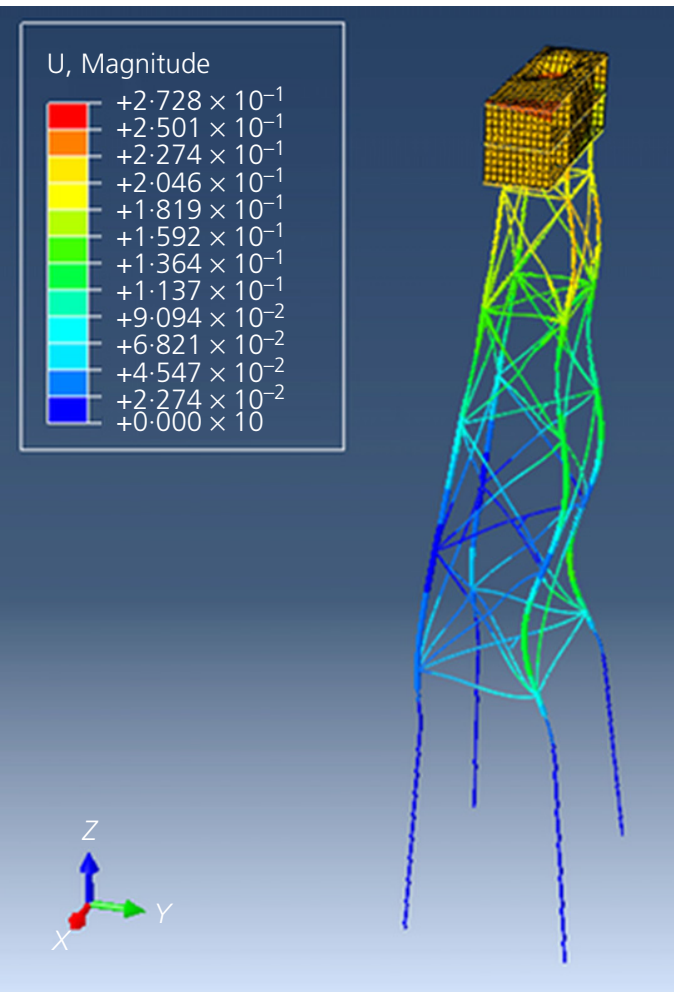

(a)

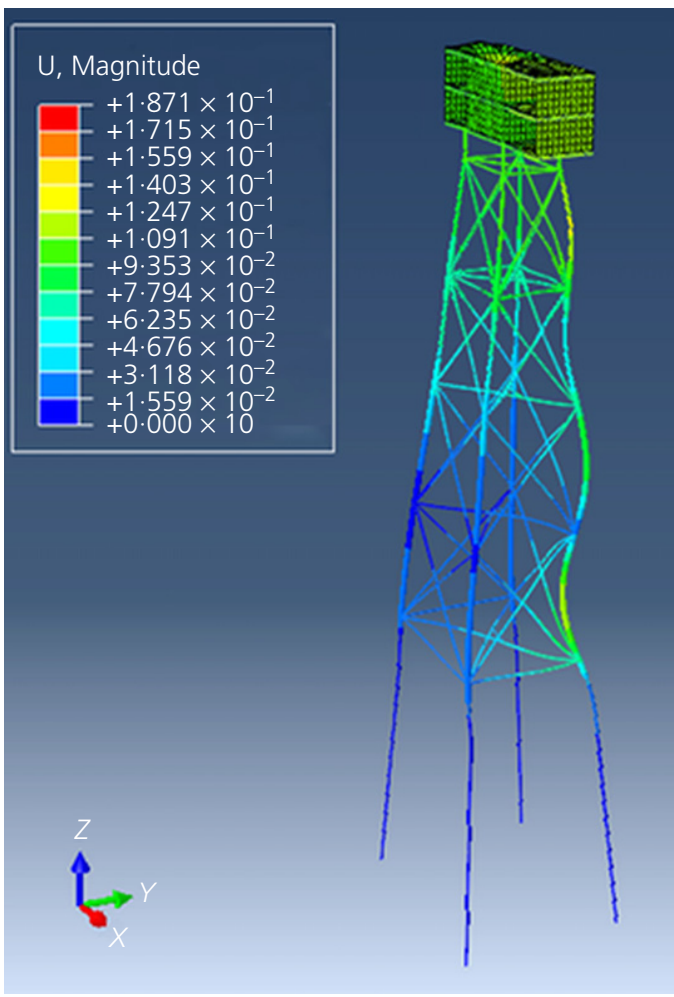

(b)

Figure 11. Response of (a) platform with imperfections in both north legs subjected to end-on south loading and (b) platform with imperfection in north-east leg subjected to broadside south-west loading. Both figures present the first converged increment after the application of environmental load. In the legend, ' $U$ ' stands for displacement. The deformation scale factor of 50 was applied to the models

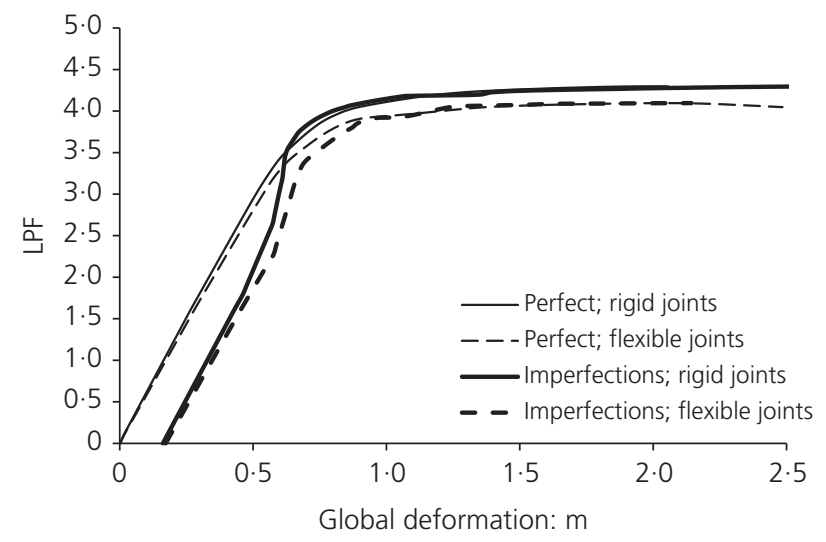

Figure 12. LPF plotted against maximum global deformation in the rigid and flexible joint models with piled foundation and without/with imperfections in both north legs subjected to end-on south loading

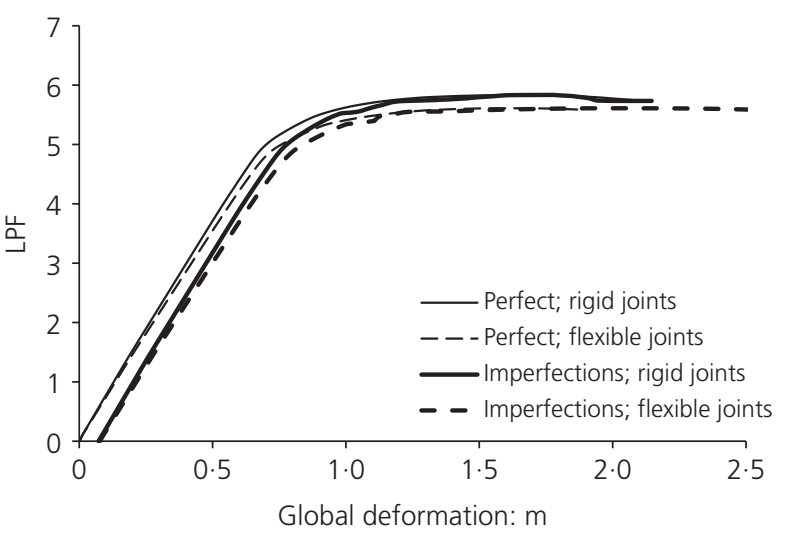

Figure 13. LPF plotted against maximum global deformation (maximum displacement in the jacket) in the rigid and flexible joint models with piled foundation and without/with imperfection in north-east leg subjected to broadside south-west loading 
regardless of the direction of loading and joint flexibility. The imperfection-induced shift of the load-deformation curve was larger in the platforms subjected to the end-on loading.

Table 6 presents the maximum base shear forces for the rigid and flexible joint models with piled foundations and imperfections subjected to eight loading cases. The base shear forces were calculated using Equation 3. The maximum base shear forces in the broadside loading cases are much larger (up to 3.4 times in the rigid joint model and 3.8 times in the flexible joint model) than those in the end-on loading cases. The joint flexibility reduced the shear forces in the broadside loading cases by up to $25 \cdot 8 \%$, while in the end-on loading cases by up to $7 \cdot 2 \%$. The comparison with the data in Table 4 indicates that the incorporation of imperfections into the platform legs increased the sensitivity of the model to joint flexibility, especially in the case of end-on loading. Moreover, the imperfections reduced the maximum base shear force in all loading cases, this is especially evident in the platforms subjected to the end-on loading.

The models with imperfections failed in similar modes but at lower load levels than the models without imperfections. This led to reduction of the maximum base shear force in the jacket, which are visually summarised in the radar-type chart given in Figure 14. The data shown in this figure are taken from Tables 4 and 6 . The average reduction in the maximum base shear force in the rigid joint model subjected to the endon loading was equal to $71.6 \%$, while in the broadside loading case only to $25 \cdot 8 \%$. In the flexible joint model, the reduction of the maximum base shear force was slightly larger, rising to 76.5 and $27 \cdot 7 \%$, respectively. It was identified in the computational simulations that the imperfections had the highest impact on the bottom section of the critical compression leg. Therefore, the reduction of the base shear force was larger in the end-on loading cases due to the development of compression forces in two legs. The detrimental effect of imperfections was connected to the initial deformation of piles

Table 6. Maximum base shear force for rigid and flexible joint models with piled foundations and imperfections

\begin{tabular}{|c|c|c|c|}
\hline \multirow[b]{2}{*}{$\begin{array}{l}\text { Loading } \\
\text { case }\end{array}$} & \multicolumn{2}{|c|}{ Base shear force: MN } & \multirow[b]{2}{*}{ Difference: $\%$} \\
\hline & $\begin{array}{l}\text { Rigid joint } \\
\text { model }\end{array}$ & $\begin{array}{l}\text { Flexible joint } \\
\text { model }\end{array}$ & \\
\hline North & $46 \cdot 62$ & $39 \cdot 53$ & $15 \cdot 2$ \\
\hline North-east & $155 \cdot 68$ & $144 \cdot 50$ & $7 \cdot 2$ \\
\hline East & $56 \cdot 08$ & $41 \cdot 61$ & $25 \cdot 8$ \\
\hline South-east & $154 \cdot 65$ & $145 \cdot 00$ & $6 \cdot 2$ \\
\hline South & $46 \cdot 70$ & $39 \cdot 65$ & $15 \cdot 1$ \\
\hline South-west & $155 \cdot 72$ & $146 \cdot 25$ & $6 \cdot 1$ \\
\hline West & 58.63 & $44 \cdot 22$ & $24 \cdot 6$ \\
\hline North-west & $157 \cdot 18$ & $148 \cdot 28$ & $5 \cdot 7$ \\
\hline
\end{tabular}

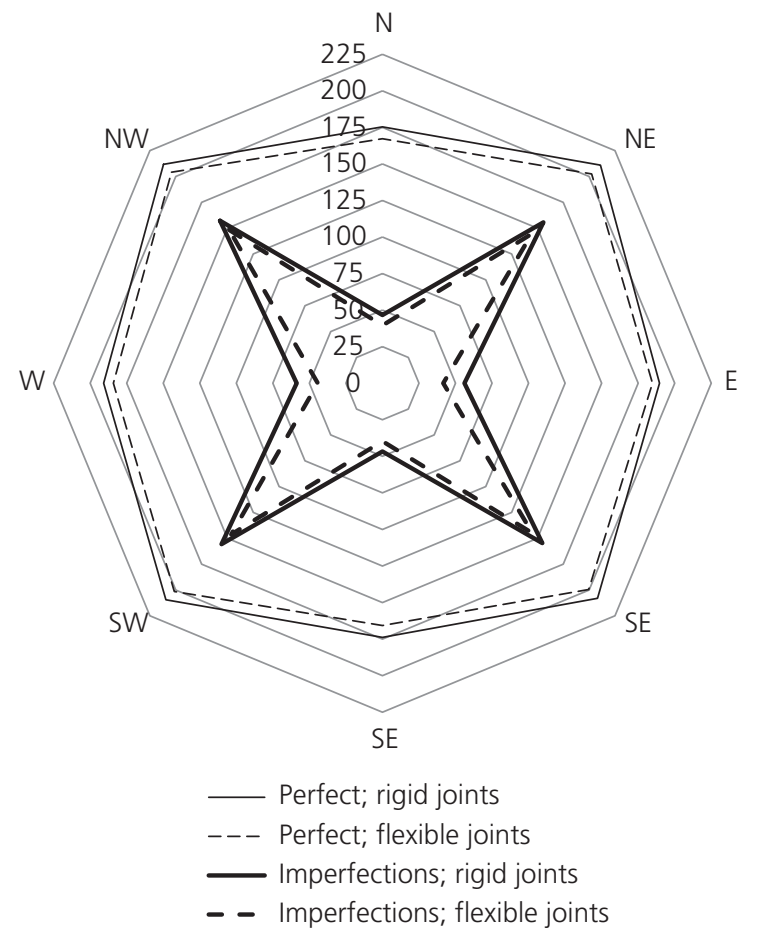

Figure 14. Maximum base shear force in the rigid and flexible joint models without/with imperfections subjected to end-on and broadside loading. The units in the chart are MN

(see Figure 5), which amplified the pile deformation induced by the environmental loading at a later loading stage. Since flexible joints allowed for higher initial deformation of piles, the imperfections had a larger effect on the flexible joint model.

\section{Conclusions}

The paper analysed the effects of joint flexibility, piled foundations and geometrical imperfections on the structural behaviour of a typical four-legged X-braced jacket-type offshore platform subjected to vertical operational (gravity, buoyancy and service) and horizontal environmental (wind and wave) loads using non-linear finite-element method. The environmental loads corresponded to the North Sea conditions and were applied in eight directions (four end-on and four broadside). The obtained failure modes of the jacket depended on the direction of the applied environmental loads and were governed by the failure (buckling) of braces in the bay where the jacket legs had smaller cross-sections.

The incorporation of joint flexibility into the model affected the yielding and ultimate strength and stiffness of the platform. Material yielding occurred in similar locations in the flexible and rigid joint models, where the yielding zones were mostly 
larger in the former model. Modelling of the jacket members using shell elements, as opposed to beam elements, enabled capturing localised yielding and buckling of legs and braces, which made joints more flexible and led to reduced structural strength and global deformability potential. Further to this, smaller shear forces developed at the base of the platform with flexible joints. As a result, disregarding joint flexibility in modelling of offshore jacket platforms can result in overestimation of platform strength, deformability and shear capacity.

The piled foundation had a severe degenerative effect on the stiffness of the platform due to the base movement and rotation introduced by the piles. The extent of this effect depended on the direction of loading. The platform yielding and ultimate strength were also affected but to a smaller degree. The strength reduction was only significant in the rigid joint model.

The geometrical imperfections were introduced in the compression legs of the jacket. Each imperfect leg was most severely affected in the most loaded segment in the bottom bay leading to the increased rotation of the joints and bending of the leg, braces and the pile. The imperfections increased the initial deformation of the jacket in the elastic range, while the effect on the strength and stiffness was insignificant. The jacket with imperfections in compression legs suffered significant reduction in shear capacity, especially when the environmental load was applied in the end-on directions. The imperfections had slightly larger effect on the model with flexible joints due to higher deformability of the structure.

In conclusion, the findings presented in this paper suggest that joint flexibility, piled foundations and geometrical imperfections should be accounted for both in the design of new and when assessing existing offshore jacket platforms, since disregarding these factors may lead to overly optimistic predictions.

\section{REFERENCES}

Abaqus (2012) Abaqus Documentation, Version 6.12. Hibbit, Karlsson and Sorensen, Pawtuchet, RI, USA.

Azadi MRE (1998) Analysis of Static and Dynamic Pile-Soil-Jacket Behaviour, Doctoral Engineering Thesis, Norwegian University of Science and Technology, Trondheim, Norway.

Bolt HM (1995) Results from large scale ultimate strength tests of K-braced jacket frame structures. Annual OFFSHORE Technology Conference, Houston, TX, USA, vol. 2, pp. 797.

Bolt HM, Billington CJ, Ward JK, Great Britain, Health and Safety Executive, Billington Osborne-Moss Engineering Limited (1996) A Review of the Ultimate Strength of Tubular Framed Structures. HSE Books, UK.

Bouwkamp J, Hollings J, Maison B and Row D (1980) Effects of joint flexibility on the response of offshore towers. Offshore Technology Conference, Houston, TX, USA.

BSI (2007) BS EN ISO 19902:2007: Fixed steel offshore structures. BSI, London, UK.
Chandrasekaran S (2015) Dynamic Analysis and Design of Offshore Structures, Ocean Engineering \& Oceanography. Springer India, New Delhi, India.

Clauss G, Lehmann E and Östergaard C (1992) Offshore Structures: Volume I: Conceptual Design and Hydromechanics. Springer-Verlag, London, UK.

Dier AF and Hellan O (2002) A non-linear tubular joint response model for pushover analysis. ASME Proceedings of the 21st International Conference on Offshore Mechanics and Arctic Engineering, Oslo, Norway, pp. 627-634.

Dier AF and Lalani M (1998) New code formulations for tubular joint static strength. Tubular Structures -International Symposium 8: $107-116$.

Douglas JF (2011) Fluid Mechanics. Prentice-Hall, Harlow, UK; New York, NY, USA.

Ersdal G (2005) Assessment of Existing Offshore Structures for Life Extension. University of Stavanger, Norway.

Gilbert RB, Chen JY, Materek B et al. (2010) Analysis of potential conservatism in foundation design for offshore platform assessment. In Offshore Technology Conference. Offshore Technology Conference, Offshore Technology Conference, Houston, $T X, U S A$, https://doi.org/10.4043/20861-MS.

Hellan $\varnothing$ (1995) Non-Linear Pushover and Cyclic Analysis in Ultimate Limit State Design and Reassessment of Tubular Steel Offshore Structures. Department of Marine Structures, Trondheim University, Trondheim, Norway.

Holmås T (1987) Implementation of Tubular Joint Flexibility in Global Frame Analysis (No. 87.1). The Norwegian Institute of Technology, Springfield, VA.

Holmås T, Remseth SN and Hals TE, Selskapet for industriell og teknisk forskning ved Norges tekniske høgskole (1987) Approximate Flexibility Modelling of Tubular Joints In Marine Structures. U.S. Dept. of Commerce, National Technical Information Service, Springfield, VA, USA.

Jusoh I and Wolfram J (1996) Effects of Marine Growth and Hydrodynamic Loading on Offshore Structures. Faculty of Mechanical Engineering, UTM.

Lancaster JF (2000) Engineering Catastrophes: Causes and Effects of Major Accidents. CRC Press; Abington Press, Boca Raton, FL, USA; Cambridge.

Lloyd JR and Clawson WC (1983) Reserve and residual strength of pile founded offshore platforms. In International Symposium, the Role of Design, Inspection, and Redundancy in Marine Structural Reliability, Washington, DC, USA, pp. 157-196.

Mendoza Espinosa J (2017) Evaluation of the Fatigue Resistance of Offshore Jacket Joints by Numerical Approaches. Masters Thesis, TU Delft.

Mirtaheri M, Zakeri HA, Alanjari P and Asareh MA (2009) Effect of joint flexibility on overall behavior of jacket type offshore platforms. American Journal of Engineering Application Sciences 2: $25-30$.

Mostafa YE and El Naggar MH (2004) Response of fixed offshore platforms to wave and current loading including soil-structure interaction. Soil Dynamics and Earthquake Engineering 24: 357-368, https://doi.org/10.1016/j.soildyn.2003.11.008.

Nelson A (2003) Technical Performance Measures for North Sea Jacket Structures. Great Britain, Health and Safety Executive, EQE (Firm), UK.

Norske Veritas (1999) Ultiguide: Best Practice Guidelines for Use of Non-Linear Analysis Methods in Documentation of Ultimate Limit States for Jacket Type Offshore Structures. Det Norske Veritas, Hovik, Norway. 
OETB (Offshore Energy Technology Board) (1990)

Background to a New Static Strength Guidance for Tubular Joints in Steel Offshore Structures. Offshore Energy Technology Board, Department of Energy, London, UK.

OGUK (Oil \& Gas UK) (2017) Decommissioning Insight 2017.

The UK Oil and Gas Industry Association, UK.

Paté-Cornell ME (1993) Learning from the piper alpha accident: a postmortem analysis of technical and organizational factors. RISA Risk Analysis 13: 215-232.
Skallerud B and Amdahl J (2002) Nonlinear Analysis of Offshore Structures. Research Studies Press, Baldock, Hertfordshire, UK; Philadelphia, PA, USA.

Stacey A, Birkinshaw M and Sharp JV (2008) Life extension issues for ageing offshore installations. In Proceedings of OMAE2008. Proceedings of the 27th International Conference on Offshore Mechanics and Arctic Engineering, Estoril, Portugal.

Ueda Y and Rashed S (1990) Modern Method of Ultimate Strength Analysis of Offshore Structures. Welding Research Institute, Osaka University, Japan.

\section{How can you contribute?}

To discuss this paper, please email up to 500 words to the editor at journals@ice.org.uk. Your contribution will be forwarded to the author(s) for a reply and, if considered appropriate by the editorial board, it will be published as discussion in a future issue of the journal.

Proceedings journals rely entirely on contributions from the civil engineering profession (and allied disciplines).

Information about how to submit your paper online is available at www.icevirtuallibrary.com/page/authors, where you will also find detailed author guidelines. 